\title{
LIV. On the interference-rings, described by Haidinger, observable by means of plates whose surfaces are absolutely parallel
}

\section{Lord Rayleigh O.M. Pres.R.S.}

To cite this article: Lord Rayleigh O.M. Pres.R.S. (1906) LIV. On the interference-rings, described by Haidinger, observable by means of plates whose surfaces are absolutely parallel, Philosophical Magazine Series 6, 12:71, 489-493, DOI: 10.1080/14786440609463563

To link to this article: http://dx.doi.org/10.1080/14786440609463563

曲 Published online: 16 Apr 2009.

Submit your article to this journal $[\pi$

Џll Article views: 5

Q View related articles $\sqsubset$

Citing articles: 4 View citing articles $\sqsubset$ 
LIV. On the Interference-Rings, described by Haidinger, observable by means of Plates whose Surfaces are absolutely Parallel. By Lord Rayleigh, O.M., Pres.R.S. *

[Plate XVI.]

THE importance which these rings have acquired in recent years, owing to the researches of Michelson and of Fabry and Perot, lends interest to the circumstances of their discovery. It seems to be usually supposed that Haidinger merely observed the rings, without a full appreciation of the mode of formation. Thus Mascart $\dagger$ writes: "C'est par ce procédé, que Haidinger les a observées le premier avec une lame de mica, mais sans en donner la véritable explication." A reference to the original papers will, I think, show that Haidinger, in spite of one or two slips, understood the character of the rings very well, and especially the distinction between them and the rings usually named after Newton and dependent upon a variable thickness in the thin plate.

In the first memoir (Pogg. Ann. Ixxvii. p. 219, 1849) the bands formed by reflexion are especially discussed. A spiritflame with salted wick, seen by reflexion at considerable obliquity in a mica plate, is traversed by approximately straight bands running perpendicularly to the plane of incidence. Talbot had observed phenomena in many respects similar.... But the yellow and black lines, observed by Talbot in thin blown glass, differ in character from the lines from mica, though both are dependent upon the interference of light. In the case of the glass the interference is due to the fact that the thickness of the glass is variable, and the lines are localised at the plate. The lines from the mica behave differently. However the plate may be turned round in its own plane, the yellow and dark lines remain perpendicular to the plane of incidence. The two surfaces of the mica are absolutely parallel to one another, and accordingly the phenomenon is the same in all azimuths. The lines appear sharper and more distinct, the nearer the mica be held to the eye, in contradistinction to the lines from glass which then become more and more indistinct and finally disappear.

The bands are due to interference of light reflected at the two surfaces. The difference of path for the rays reflected at the front and back surfaces amounts for the bright bands to a whole number of wave-lengths plus a half wave-length,

* Communicated by the Author.

† Ann. de Chim. t. xxiij. p. 128 (1871). 
for the dark bands to a whole number of wave-lengths simply.

The dark parallel lines are seen with the greatest distinctness in the reflected light. There is then a striking contrast between the reflected bright light and the black due to its absence, the plate being backed by a dark ground. If the plate is held in an oblique position between the eye and the flame, the parallel lines are seen directly, but there is a much less striking contrast with the bright parts.

At this time Haidinger had not succeeded in seeing the complete rings, but in a later memoir (Pogg. Ann. xcri. p. 453,1854 ) he returns to the subject and shows how the obstacle to the incident light caused by the head of the observer may be overcome. with the aid of a glass plate inclined at $45^{\circ}$. The incident light on its way to the mica is reflected at the glass plate, while on its return it traverses the plate and so reaches the eye.

The observation of the transmitted rings is of the simplest possible character. It is sufficient to look through the plate of mica at a sheet of white paper illuminated either from in front or from behind by the homogeneous light of the spirit, flame. The rings are complementary to those seen by reflexion. They are, however, much less intense, being due to the interference of the powerful directly transmitted light with the much feebler light twice reflected in the interior of the plate.

The distinction between "Berührungs-ringe" and "Plattenringe" is again emphasised, the former depending upon a variable thickness, the latter upon a variable obliquity. We may well agree with Haidinger when he concludes: "Die Plattenringe am Glimmer bilden also eine Classe von Interferenz-Erscheinungen für sich, die einfachste, die es geben kann, wie ich diess in der vorhergehenden Zeilen mit hinreichender Evidenz nachgewiesen zu haben glaube"*.

It is interesting to remark that Haidinger's rings, rather than Newton's, are those directly explained by the usual calculation due to Young, Poisson, and Airy, where plane waves of light are supposed to be incident upon a parallel plate. The application to a plate of variable thickness cannot be more than approximately correct. That the indirect rather than the diract application should have been (until lately)

* It should perhaps be noted that Haidinger omits the factor (refractive index) in the expression for the retardation on which the interference depends, viz. $2 \mu e \cos \theta$, where $e$ denotes the thickness of the plate and $\theta$ the angle of refraction. Also that, probably by a slip of the pen, he speaks of the retardation as increasing with the obliquity. 
the more familiar may be attributed to the great difficulty of preparing artiticial surfaces of the necessary accuracy. The demand for equality of thickness is satisfied naturally in plates of mica obtained by cleavage, and again when a layer of water rests upon mercury*.

There is no difficulty in repeating Haidinger's observation. The transmitted rings are best seen by holding the mica close to the eye (focused for infinity) and immediately in front of a piece of finely ground glass behind which is placed a salted Bunsen flame $\dagger$. If the mica be very thin, of the kind sold by photographic dealers-perhaps $.05 \mathrm{~mm}$. thick, the rings are on too large a scale. But if the plate be inclined to the line of vision, the circular arcs are well seen and, owing to the enhanced reflexions, exhibit more contrast than is attainable at perpendicular incidence. When it is desired to examine the complete rings, the plate should be much thicker. I have experimented especially with two plates, $\cdot 185 \mathrm{~mm}$. and $\cdot 213 \mathrm{~mm}$. thick, and have observed some novel effects, evidently dependent upon the double refraction of the mica, hitherto it would seem not taken into account.

Very eursory observation on these plates, held squarely, showed that with the thinner $185 \mathrm{~mm}$. plate the inner rings were well seen, while with the thicker one they were not. Familiarity with Fabry and Perot's apparatus at once suggested that the complication might be due to a double system of rings, corresponding to the two D lines, accidentally coincident in the first case but interfering with one another in the second. It soon appeared, however, that the duplicity of sodium light was not the cause. The substitution of a helium vacuum-tube for the salted Bunsen made no material difference. And further, calculation showed that the two soda systems would be practically in coincidence in both cases. Thus, if we take as the mean thickness $\cdot 20 \mathrm{~mm}$. and a refractive index of 1.5 , the relative retardation is $2 \times 1.5 \times \cdot 20$ or $\cdot 60 \mathrm{~mm}$. The wave-length for soda light is $5.9 \times 10^{-4} \mathrm{~mm}$., so that the order of the rings under observation is about $60 \div 5 \cdot 9 \times 10^{-4}$, or very near 1000 . Now the wave-lengths of the two soda lines differ by about one-thousandth part, and thus the two ring-systems are almost in coincidence. As the thickness increases from $\cdot 20 \mathrm{~mm}$., the concordance would be lost, but

* 'Nature,' xlviii. p. 212 (1893); 'Scientific Papers,' iv. p. 54.

† According to Prof. Wood's recommendation the calting is best effected with the aid of a piece of asbestos, previously soaked in brine, wrapped round the tube of the Bunsen and forming a prolongation of it. 
complete discordance would not occur until a thickness of :30 mm. was reached. Practically in both cases the ringsystems may be considered to be in coincidence. But although the duplicity of the soda line is not the cause, there is in fact a second ring-system, owing to the double refraction of the mica. That this is the case is easily proved with the aid of a nicol capable of rotation about its axis. When the ring-system of the thicker plate is examined with the nicol, there are four portions at right angles to one another at which the inner rings become distinct. But in adjacent positions, $i$. $e$. positions distant $90^{\circ}$, of the nicol the ringsystems seen are different. If one has a bright centre, the other has a dark centre. When no nicol is used, or when the nicol occupies positions at $45^{\circ}$ to those above mentioned, the ring-systems interfere, and little or nothing is visible, at any rate near the centre. When the thinner plate is employed, the ring-system is really double, but does not appear to be so, since the components are approximately in coincidence. In this case the appearance is but little altered by the use of a nicol however held.

It is only near the centre of the system that the rings are obscured when the thicker plate is used without a nicol. Further out, the rings become distinct enough. A closer examination shows, however, that this statement needs qualification. Along four directions, apparently at right angles, radiating from the centre, there are regions of no definition. These regions are narrow, so narrow that they might at first escape observation, and they constitute, as it were, spokes of the ring-system. It was natural to suppose that these spokes represented places where the rings of each system bisected the intervals between the rings of the other system-a conjecture supported by the fact that the spokes disappeared when a nicol was introduced in the positions suitable for rendering the inner rings distinct. The effect was to make distinct the outer rings also all round the circumference. Further confirmation was afforded by the introduction behind the unica of cross-wires and a collimator-lens, serving to indicate a fixed direction. This was pointed at a spoke, so that without a nicol no bands were visible in the neighbourbood of the eross-wires. The nicol was then introduced in such a position as to give maximum distinctness, and the cross-wires adjusted to coincide with the centre of a bright band. A rotation of the nicol through $90^{\circ}$ showed that in the band-system then visible the cross-wires marked the centre of a dark in place of a bright band. 
The disappearance of the rings at the places where the brightest places in one system bisect the intervals between the brightest places of the otluer system depends of course upon the width of the bright rings being not much less than half of the complete period. If, as in the Fabry-Perot apparatus, the bright rings are much narrower, both systems should become visible. I thought therefore that it would be of interest to silver lightly on both sides a portion of the thicker plate, the more as, apart altogether from the spokes, the whole effect would be improved owing to the enhanced reflexions. By the chemical method, as ordinarily used for silvering glass surfaces, I did not succeed; but there was no difficulty in getting the required deposits by the method of electrical discharge in vacno using a silver cathode *. With the silvered plate the nature of the whole phenomenon, including the character of the spokes, was evident on simple inspection. At the spokes both ring-systems conld now be seen, forming a compound system of half the original period. If we neglect the circular character of the rings, the effect may be imitated with straight ibands, as shown in Pl. XVI. From a piece of striped stutf, in which the bright bands are of width equal to about a quarter of the complete period, a photographic negative was taken. The prints from this negative are made with two exposures, between which the paper is slightly rotated. In this way two systems of bands are impressed, crossing one another at a small angle.

The fact that the two concentric ring-systems cross one another proves of course that they cannot both be strictly circular. Complete circularity in all cases would require a wave-surface in the form of two concentric spheres, and such is not the character of optical double refraction. An exception would occur in the case of a uniaxal crystal cut perpendicularly to the axis, which would then be an axis of symmetry for the whole phenomenon. Another comparatively simple case would arise if the surfaces of the plate were parallel to the axis of a uniaxal crystal. In general one at least of the ring-systems would be elliptical as in the observations; and it would seem that the systems need not even be concentric. A more minute theoretical examination might be of some interest, especially in comparison with observations upon a plate whose optical constants were known.

Terling Place, Witham.

Oct. 10, 1906.

* Wright, Amer. Journ. Sci. xiv. p. 169 (1877). 
Phil. Mag. Ser. 6, Vol. 12, Pl. XIV.

FIG. 1.
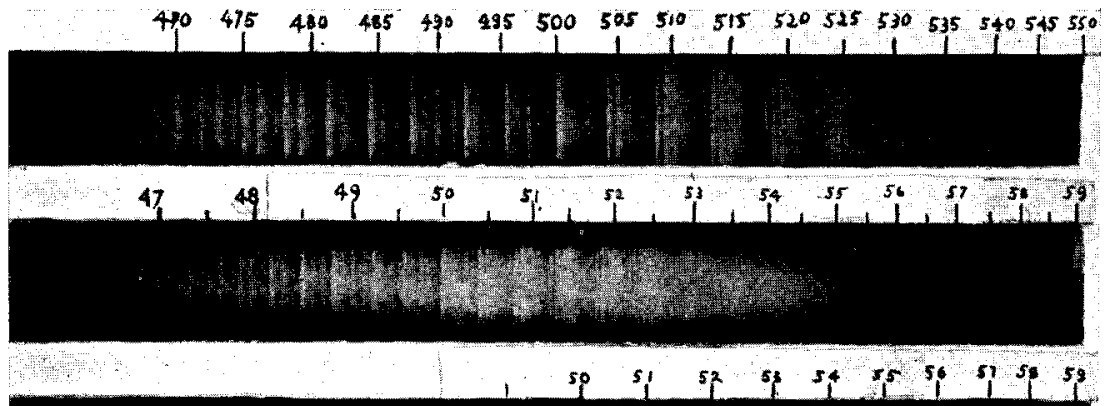

Hedse

$+3 x^{2}+2$

and

it 1

程

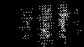

FIG. 2.

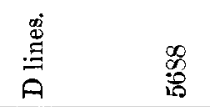

$\rightarrow$

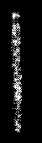

